\title{
IAMJ
}

INTERNATIONAL

AYURVEDIC

MEDICAL JOURNAL

\section{A CASE REPORT ON OPEN PORES}

\author{
Nabeela Sultan ${ }^{1}$,Shagufta Aleem ${ }^{2}$ \\ ${ }^{1}$ PG Scholar, ${ }^{2}$ Professor \\ Department of Amraz E Jild Wa Tazeeniyat, Ajmal Khan Tibbiya College Aligarh Muslim University, Aligarh, \\ UP, India
}

\section{Corresponding Author: nabeelasultan243@gmail.com}

\section{https://doi.org/10.46607/iamj4309122021}

(Published Online: December 2021)

Open Access

(C) International Ayurvedic Medical Journal, India

Article Received: 26/11//2021 - Peer Reviewed: 10/12/2021 - Accepted for Publication 11/12/2021

\section{Check for updates}

\section{ABSTRACT}

Enlarged pores of facial skin always remain a matter of concern from both dermatologic and cosmetologic points of view. There were many conditions that are difficult to treat in which facial pores enlarge among them most common condition is acne vulgaris. This condition put a negative impact on a person's quality of life and as well as also socially devastating for many individuals as it affects the physical appearance of a person. Although enlarged pores are not of medical concern it is considered as a more cosmetic concern. There are many available possible treatment options for enlarged pores but this case report is based on clinical evaluation of radiofrequency therapy in treating enlarged skin pores. In this report, three sessions of therapy every week for 3 weeks were applied. The results show a gradual decrease in the size of pores with almost clear skin.

Keywords: acne vulgaris, enlarged pores, facial pores, radiofrequency

\section{INTRODUCTION}

The dermatologist, cosmetologist and aestheticians find it difficult or even challenging in treating enlarged open pores. The word pore is used by many individuals worldwide although pore can be defined as an aperture 
for the input and output of gases or fluids. In association with skin, these orifices comprise tiny ostea, pilosebaceous follicles or eccrine sweat glands. Regarding previous work, skin pores can be seen easily with naked eyes ranging from 250-500 micrometre in size (Filament et al., 2015). In another word, the term pore refers to the pilosebaceous follicular enlargement with or without horny impactions that can be easily seen on the scalp and face by naked eyes. The potential causes of the pathophysiology behind this condition include acne, chronic photodamage, chronic radiodermatitis, vitamin A deficiency, seborrhea and loss of elasticity and tension of the skin. The size of the pore is very much affected by hormonal influence like high sebum output levels in men are testosterone-driven and also in females, the pore size increases substantially during the ovulatory phase of the menstrual cycle because progesterone affects sebaceous gland activity. It is also seen in many individuals that acne and pore enlargements are interlinked and also pore density and their size ranges diversely among ethnicities like Chinese women exhibit lower pore size and black individuals have large pore size (Dong et al.,2016).

\section{Case description:}

In February 2020, a female patient of 25 years old name Samrah came to the AKTC Amraaz E Jild Wa Tazeeniyat OPD with complaints of open pores over the face and these pores are occur as a result of acne vulgaris. She was suffering from this condition for a long time and had already taken treatment for the present condition but didn't get relief from any local application and oral preparation. On local examination of the skin, there was no localized lesion, no local inflammation, scaling, hypo-pigmented marks and itching. She gives a positive history of prior treatment for PCOD from a gynaecologist but there at present she had no complaint regarding gynaecology. There is no history of increased thirst, weight, frequency of micturition, and hunger. On systemic examination, there is no abnormality detected in CVS, Respiratory system and GIT and there is also no complaint regarding neurology like seizures, transient paralysis and syncope. She also does not have any autoimmune disorders like thyroid, diabetes, vitiligo and alopecia areata. On thorough examination, she was diagnosed with post-acne enlarged pores. There is no need to admit her that's why she was allowed to come 3 times a week for at least 3 weeks for therapy and the prescribed therapy was Radiofrequency without being given any oral and local application drug.

\section{MATERIAL AND METHOD:}

Patients with post-acne enlarged pores received 3 sittings of radiofrequency therapy per week for three weeks and outcome assessment and comparison include photography and changes noted with untreated lesions.

Duration of study: 3 weeks

RESULT: The result shows progressive improvement in condition with the use of the above-mentioned therapy.

\section{DISCUSSION}

Acne is the most common disorder of skin affecting almost $90 \%$ of the individuals in their teenage between 10 to 17 years in females and 14 to 19 years in males. Most of the time it affects the face and leads to postacne scars up to $95 \%$ of individuals. Soreness, itching and pain are the common symptoms of acne vulgaris and blackheads or open come domes are perceived easily and they appear due to oxidation of open come domes (Hui et al.,2017; Jayakar et al.,2007). There are almost multiple options are available to control and treat this condition such as chemical peels, dermabrasion, dermal grafting, punch excision, punch grafting and micro-needling with a derma roller can be used. The RF treatment is the alternative option available apart from above mentioned conventional treatment options. It offers deeper penetration in the dermis by using a single electrode and a grounding pad on the skin. RF induce tissue tightening and counter changes via dermal collagen remodelling. It produces heat of different levels under the skin which causes denaturation of collagen that ultimately results in shrinkage and required rejuvenation and it heats the dermis to the point to obtain the required therapeutic effect without causing harm to surround tissues. It also induces new 
collagen formation via heating fibroblast to stimulate collagen production (Gorgu et al., 2019).

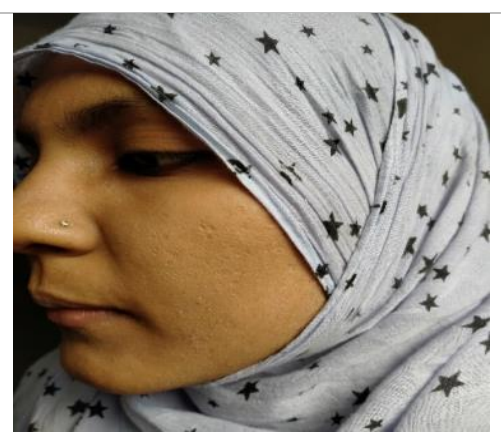

First week Pictures before treatment.

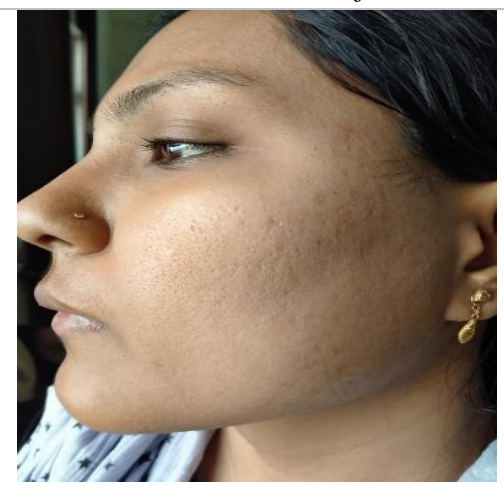

Second-week Pictures during treatment.

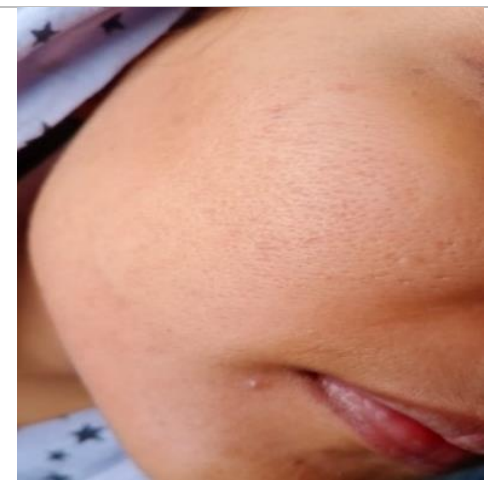

Third-week pictures after treatment.

\section{CONCLUSION}

The Used therapy i.e. radiofrequency was found to be effective in the management of post-acne enlarge pores which suggest their activity in increasing collagen in the skin. The therapy was well-tolerated and no adverse effects were seen during the course of the study. There is a need for further study on a larger sample size with longer follow-up is required. So that the complete cure

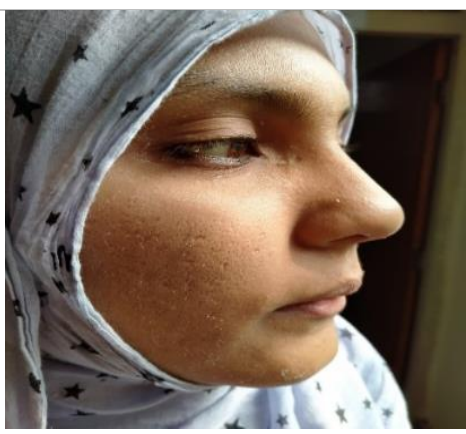

First week Pictures before treatment.

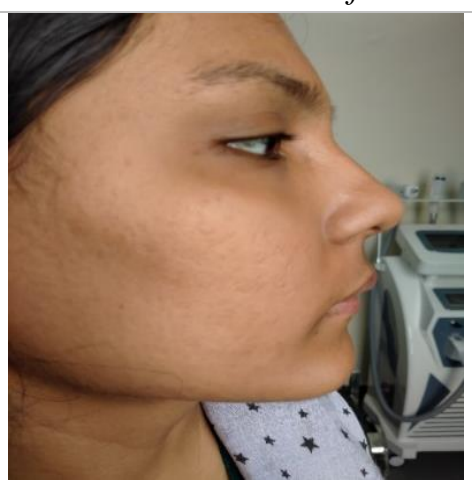

Second-week Pictures during treatment.

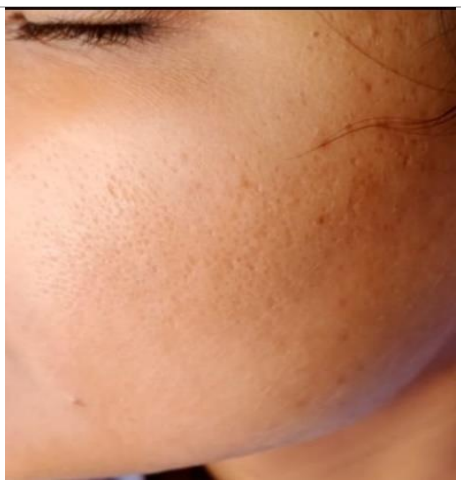

Third-week pictures after treatment.

with the use of this therapy can be achieved which will give more confirmation regarding the efficacy and safety of used therapy.

\section{Acknowledgment:}

I am very thankful to Principal Ajmal Khan Tibbiya College for the smooth and successful running of the Hospital and the departments, the 
chairmen department of Amraz E Jild Wa Tazeeniyat, for allowing me to perform my study and my co-author for proper guidance and collaboration. I am also thankful to the patient who is enrolled in our study.

\section{REFERENCES}

1. Dong J, Lanoue $\mathbf{J}$ and Goldenberg G, Enlarged facial pores: an update on treatments. Cutis. 2016 Jul;98(1):33-6.

2. Flament F, Francois G, Qiu H, Ye C, Hanaya T, Batisse D, Cointereau-Chardon S, Seixas MD, Dal Belo SE, Bazin R, et al., Facial skin pores: a multiethnic study. Clin Cosmet Investig Dermatol. 2015 Feb 16; 8:85-93.

3. Gorgu, Metin, "“Radiofrequency: Review of Literature. "Turkish Journal of Plastic Surgery, vol. 27, no. 2, 2019. p.62+.

4. Hui RW*, Common misconception about acne vulgaris: A review of the literature. Clin Dermatol Rev 2017; 1:33-6.

5. Jayakar Thomas. "Pediatric Dermatology ward rounds". Jaypee Brothers medical publisher (P) LTD. NEW DELHI. 2007, p. 7-8

\section{Source of Support: Nil}

\section{Conflict of Interest: None Declared}

How to cite this URL: Nabeela sultan \& Shagufta Aleem: A Case Report On Open Pores. International Ayurvedic Medical Journal \{online\} 2021 \{cited December 2021\} Available from: http://www.iamj.in/posts/images/upload/3183_3186.pdf 